\title{
Resuscitating the Earth: A Linguistic Analysis of Selected Poems in Niyi Osundare's The Eye of the Earth
}

\author{
Abosede Adebola Otemuyiwa (Corresponding author) \\ Department of English, Ikeji-Arakeji, Joseph Ayo Babalola University, P.M.B 5006, Ilesa, Osun-State, Nigeria \\ E-mail: otemuyiwa2011@yahoo.com \\ Adetokunbo O. Akinyosoye \\ General Studies Department, Moshood Abiola Polytechnic, Abeokuta, Ogun-State, Nigeria \\ E-mail: toksfunm@gmail.com
}

Received: 09-11- 2014

Published: 01-07- 2015
Accepted: 02-02- 2015

doi:10.7575/aiac.ijalel.v.4n.4p.98
Advance Access Published: February 2015

URL: http://dx.doi.org/10.7575/aiac.ijalel.v.4n.4p.98

\begin{abstract}
This study analyzed three of Niyi Osundare's poems in the 'Eye of the Earth'. We considered the syntactic patterns and semantic applications used in the selected poems to drive home the thematic pre-occupation of the poet. Hassan (1985) asserts that linguistic stylistics has its major purpose of relating language use in literary texts to its artistic function. The selected poems are Let Earth's Pain Be Soothed, First Rain and Meet me at Okeruku. Linguistic Stylistic Analytical Framework is used for the analysis. Use of diction, meanings and figurative expressions of the poems were the focus. Result of the analysis revealed that to discuss the language of poetry is to reveal those stylistic features which conform to and deviate from the norms of the language of poetry. The analysis indicated that linguistic stylistics operates on some key concepts like deviation or foregrounding.
\end{abstract}

Keywords: Osundare's poems, linguistic, syntactic, grammatical, semantic, patterns, figurative expressions

\section{Introduction}

The importance of linguistic stylistic for the study of Literature in English cannot be over-emphasized. Linguistic Stylistic started in the early 1960s as an approach to complement literary criticism. Linguistics is defined as the scientific study of language. Hence, it employs objective and verifiable methods of analysis in analyzing and interpreting texts. As such, linguistic stylistic is an analytical approach used by scholars to objectively study both literary and non-literary texts and materials. Awonuga (1988) observes that one important advantage of linguistic stylistics for the study of literary texts is the opportunity it provides the readers to systematize their response to the various works of literature that they have cause to study. . Chapman (1973) believes that deviation occurs due to the fact that poets enjoy the poetic license to manipulate rules of grammar and conventions generally observed by users of the language. Leech (1981) claims that the liberties poets have taken with language have been of immense varieties and sometimes reached a pathological degree of abnormality. One can say that 'deviation' is purposely used for comprehension and for creation of beauty in the use of language. Deviation occurs at all levels of language analysis. So we have semantic, grammatical, graphological, lexical and phonological deviations.

\section{Theoretical Framework}

Linguistic stylistics handles the relationship between literary and ordinary language more effectively than other approaches as it is found to be a very reliable method of literary appreciation and interpretation. Crystal (1974) defines linguistics as the scientific study of language. He also asserts that scientists arrive at a conclusion after they might have taken various stages, which include observation, formulation of hypothesis, experimentation and finally formulation of results, which are then integrated into the body of scientific knowledge. Linguistic stylistics is the study of linguistic pattern of either non-literary or literary texts.

\section{Foregrounding}

Foregrounding is that psychological effect resulting from the conspicuous elements that hold a promise of stylistic relevance, and thereby rouse the readers' interest or emotions. Such foregrounded elements often include a distinct patterning or parallelism in a text's typography, sounds, word choices, grammar, or sentence structures, repetition of some linguistic elements and deviations from the rules of language in general. Foregrounding generally means violation of norms. It should be noted that violation of norms (foregrounding) can still occur in the same linguistic environment within the unviolated norms, since the unfamiliar could be described in relation to the familiar. We have the deviational and non-deviational foregrounding. Deviational foregrounding is where the reader's attention is arrested by way of violating the rules and norms of the language, whereas non-deviational foregrounding is the kind of structure that acquires a prominent significance in a text as a result of making use of a certain aspect of language or literary norms in such a constant and systematic manner that it attracts the attention of the reader. 


\section{1 'Let Earth's Pain Be Soothed'}

\section{$\begin{array}{lll}\mathbf{P} & \mathbf{C}\end{array}$}

1 The sky / carries / a boil of anguish

$$
\begin{aligned}
& \text { A S P } \\
& \text { 2. Let / it / burst }
\end{aligned}
$$

$$
\mathrm{S} \quad \mathrm{P} \quad \mathrm{C}
$$

3. Our earth / has never lingered / so dry

$$
\text { A }
$$

4. In the season of falling showers

$$
\mathrm{S} \quad \mathrm{P} \quad \mathrm{A}
$$

5. Clouds / journey / over trees and over hills A

6. Miserly with their liquid treasure

$$
\mathrm{S} \quad \mathrm{P} \quad \mathrm{C}
$$

7. The sky / carries / a boil of anguish

$$
\begin{aligned}
& \text { A S P } \\
& \text { 8. Let / it / burst } \\
& \text { P } \quad \text { A }
\end{aligned}
$$

9. Prostrate / like famished horses
P A
$\mathrm{S}$
10. brown hills / cast / vacant looks A

11. at balded plains where playing kids

$$
\mathrm{P} \quad \mathrm{S} \quad \mathrm{A}
$$

12. provoke / the dust / in what once was

$$
\text { A }
$$

13. the cradle of green

$$
\mathrm{S} \quad \mathrm{P} \quad \mathrm{C}
$$

14. The sky / carries / a boil of anguish

$$
\begin{array}{ccc}
\text { A } & \text { S P } \\
\text { 15. Let / it / burst } \\
\text { S } \\
\text { 16. Dust } \\
\text { S } & \text { A }
\end{array}
$$

17. dust / in brewing kitchens

$$
\mathrm{S} \quad \mathrm{A}
$$

18. dust / in eating halls

$$
\mathrm{S} \quad \mathrm{A}
$$

19. dust / in scheming boardrooms

$$
\mathrm{S} \quad \mathrm{A}
$$

20. dust / in retrenching factories

$$
\text { A }
$$

21. dust / in power brothels

$$
\mathrm{S} \quad \mathrm{P} \quad \mathrm{C}
$$

22. The sky / carries / a boil of anguish

$$
\begin{aligned}
& \mathrm{P} \quad \mathrm{S} P \\
& \text { 23. Let / it / burst } \\
& \mathrm{P} \quad \mathrm{S} \quad \mathrm{A}
\end{aligned}
$$

24. Let / it / rain today

$$
\mathrm{S} \quad \mathrm{P}
$$

25. that parched throats / may sing

$$
\begin{array}{ll}
\mathrm{P} & \mathrm{S} \\
\text { 26. Let / it / rain } \\
\mathrm{P} & \mathrm{C}
\end{array}
$$

$\mathrm{S}$

27. that earth / may heal / her silence

$$
\mathrm{P} \quad \mathrm{S} \quad \mathrm{A}
$$

$$
\text { 28. Let / it / rain today }
$$

$$
\mathrm{S} \quad \mathrm{P} \quad \mathrm{C}
$$

29.that cornleaves / may clothe / the hills

$$
\begin{aligned}
& \mathrm{P} \quad \mathrm{S} P \\
& \text { 30. Let / it / rain }
\end{aligned}
$$$$
\begin{array}{llll}
\mathrm{S} & \mathrm{P} & \mathrm{S} & \mathrm{C}
\end{array}
$$

31. that roots / may swell / the womb / of lying plains

$$
\mathrm{P} \mathrm{S} \mathrm{A}
$$

32. Let/ it / rain today

$$
\text { S P C }
$$

33. that stomachs / may shun / the rumble of thunder

$$
\begin{aligned}
& \mathrm{P} \quad \mathrm{S} P \\
& \text { 34. Let } / \text { it } / \text { rain }
\end{aligned}
$$$$
\mathrm{S} \quad \mathrm{P}
$$

35. that children / may bath and bawl and brawl

$$
\begin{array}{lll}
\mathrm{S} & \mathrm{P} & \mathrm{C}
\end{array}
$$

36. The sky / carries / a boil of anguish

$$
\begin{aligned}
& \mathrm{P} \quad \mathrm{S} P \\
& \text { 37. Let / it / burst }
\end{aligned}
$$
$\mathrm{S}$
$\mathrm{P}$
A

38. The roofs / have been silent / too long

$$
\mathrm{S} \quad \mathrm{A} \quad \mathrm{A}
$$

39. the seeds / noiseless / in the dormitory of the soil
$\mathrm{S}$
$\mathrm{P}$
A

40. the earth / has been lying / too long, and songless.

$$
\text { A }
$$

41. Time to leap, time to lilt
$\mathrm{P}$ $\mathrm{S}$
$\mathrm{P} \quad \mathrm{A}$

42. Let / the sky's boil of anguish / burst / today
$\mathrm{S}$
A $P$

43. The pain / of earth / be soothed.

\subsection{First Rain}

$\mathrm{S} \quad \mathrm{P} \quad \mathrm{C}$

1. A tingling tang / awakes / the nose

$$
\text { A } \mathrm{S} \quad \mathrm{P}
$$

2. When / the first rain / has just clipped

$$
\mathrm{C}
$$

3. The wing of the haughty dust

$\begin{array}{lll}\text { A } P & P \\ \text { a cooling / warmth / embraces }\end{array}$

$$
\text { C }
$$

5. our searching soles

A $\mathrm{S} \quad \mathrm{P}$

6. as / the land vapour / rises

$$
\text { A C }
$$

7. like / a bootless infantry

$$
\text { 8. and }
$$

A C

9. through / her liberated pores

$\begin{array}{lll}\mathrm{S} & \mathrm{P} & \mathrm{A}\end{array}$

10.our earth / breathes / again 


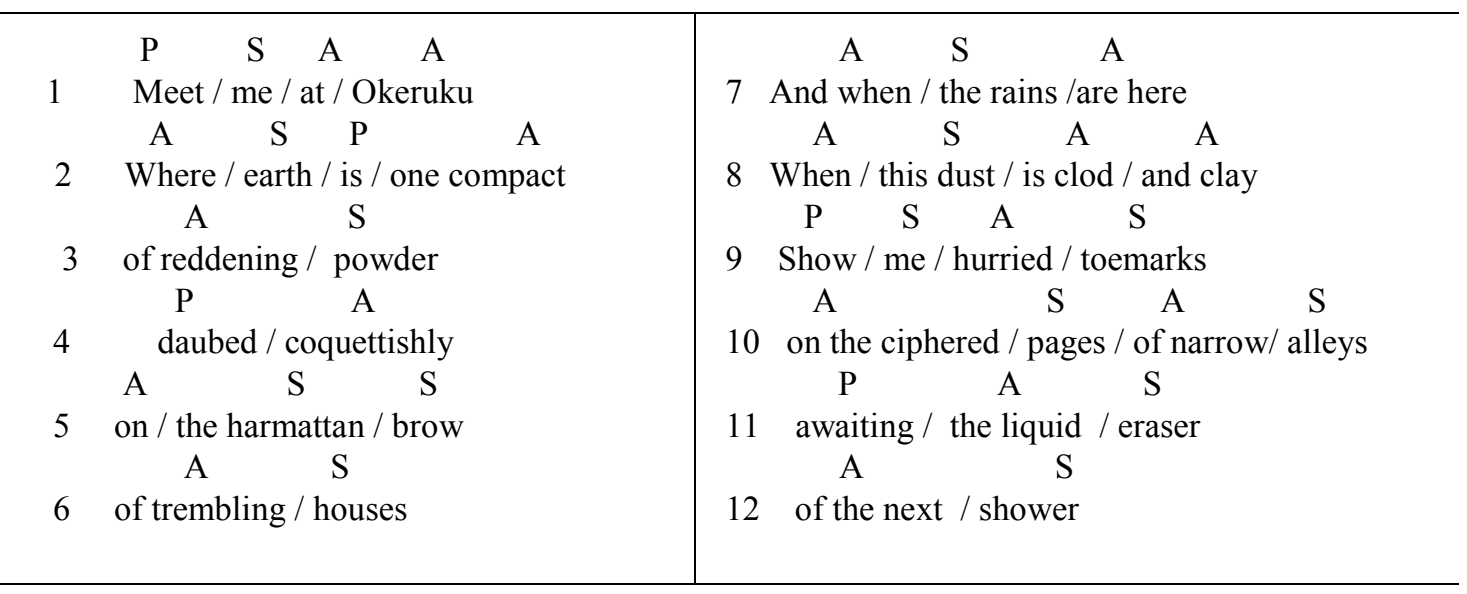

\section{Discussion}

\subsection{Linguistic Features Manifested in the Poems}

\subsubsection{Sentence / Clause Typology}

In the poem Let Earth's Pain Be Soothed, there are nine (9) SPC structure sentences. The nine lines have basic simple sentence pattern. According to Aremo (2004), non-basic simple sentences are formed through these operations: movement, deletion and insertion. In this poem, there are 14 lines of non-basic sentences, which are formed by moving the predicator before the subject (movement). Five of the lines of the poem are purely adverbial clauses. These are lines 4, 6, 11, 13, and 41. Out of the 43 lines that make up the poem 'Let Earth's Pain Be Soothed', 12 lines are starting with 'let' which make those lines to have subjectless verb (Aremo 2000). Concerning the use of commands with 'let' as the theme of the sentence or clause, Quirk et al (1976) has it that first person imperatives can be formed by proposing the verb 'let' followed by a subject in the objective case. In the poem, we have structures like, line2: Let it burst, line 24, Let it rain today, line 26, Let it rain today, all this shows the eagerness of the poet in wanting the rain to fall. Quirk et al (1976) further asserts that in every colloquial English, 'let' is sometimes used for a $1^{\text {st }}$ person singular. See the table 1 and the figure 1 below:

5.1.2 Forms and Types of Clauses Prominent in the Poems and their Functions

Table 1. Prominent Structural Patterns in Let Earth's Pain Be Soothed

\begin{tabular}{ll}
\hline Structural Patterns & $\begin{array}{l}\text { Number of Occurrences } \\
\text { \% Usage }\end{array}$ \\
\hline SPC & 29.5 \\
SPA & 9.8 \\
SA & 16.9 \\
PSP & 26.7 \\
A & 16.9 \\
\hline
\end{tabular}

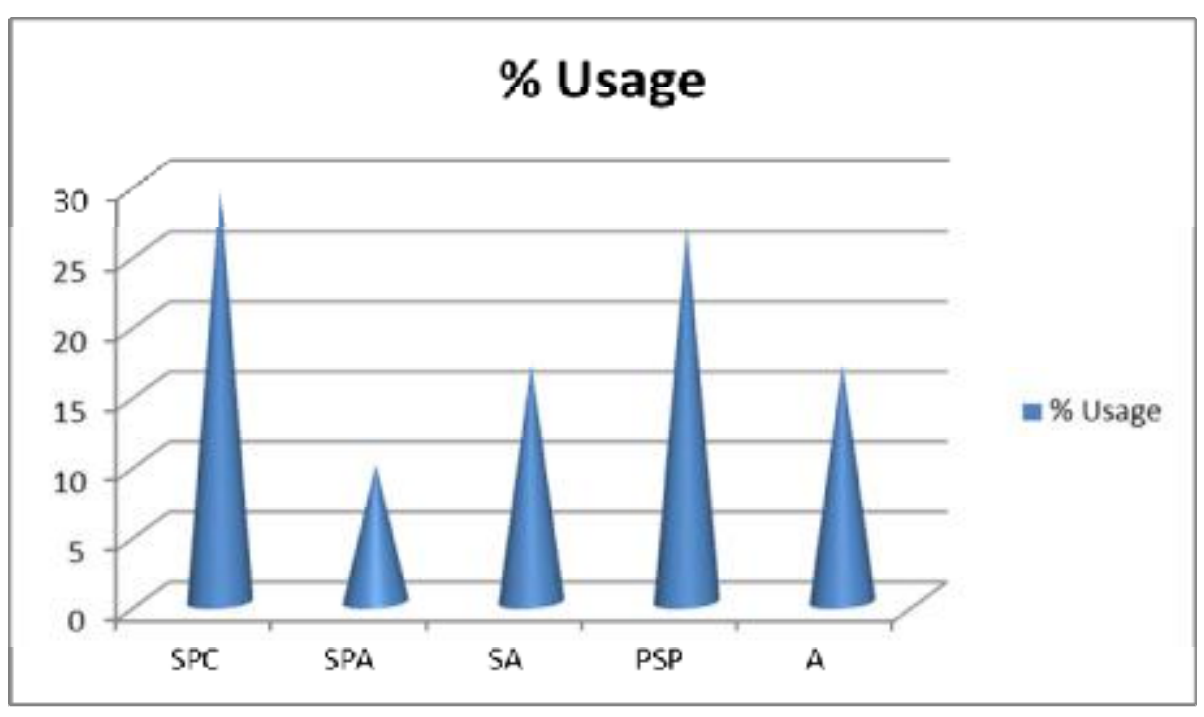

Figure 1. The Percentage Usage of Prominent Structures in 'Let Earth's Pain Be Soothed' 
The SPC structural pattern forms $29.5 \%$ of the patterns, SPA pattern forms $9.8 \%$, SA pattern forms $26.7 \%$ and A pattern form $16.9 \%$ as represented in the figure above.

5.1.3 Metaphorical Features in 'Let Earth's Pain Be Soothed'

There are some metaphorical words, phrases and clauses that run through the poem 'Let Earth's Pain Be Soothed'. Examples are: Line 1: 'The sky carries a boil of anguish', line 5: Clouds journey over trees and over hills, line 6: Miserly with their liquid treasure, line 10: brown hills cast vacant looks, line 11: at balded plains where playing kids, line 12: provoke the dust in what once was, line 13: the cradle of green. These metaphorical expressions give a kind of beauty to the poem and the run-on lines make the poem rhythmical and sonorous. This is revealed in lines: $16-21$ below:

Dust,

dust in brewing kitchens,

dust in eating halls,

dust in scheming boardrooms

dust in retrenching factories,

dust in power brothels

'Dust' is being repeated for emphasis on the bad effects that lack of rain brings to brewing kitchens, eating halls, scheming boardrooms, retrenching factories and power brothels. The poet explained that all these places are seriously affected when there is no rain. He puts the following lines as interlude in the poem after mentioning these bad effects.

The sky carries a boil of anguish,

Let it burst

Let it rain today,

He then makes a sort of digression by mentioning the good effects that can occur when there is rain from Line 24 to 33 .

Let it rain today

that parched throats may sing

Let it rain

that earth may heal her silence

Let it rain today

that cornleaves may clothe the hills,

Let it rain

that roots may swell the womb of lying plains

Let it rain today

that stomachs may shun the rumble of thunder

Let it rain

that children may bath and bawl and brawl

From line $36-43$, the poet mentioned that the roofs have been silent for too long, the seeds being noiseless in the dormitory of the soil and the earth to have been lying too long and songless. All these lines of the poem below show the extent to which the rain is needed.

line 37: Let it burst, line 38: The roofs have been silent too long, line 39: the seeds noiseless in the dormitory of the soil, line 40: the earth has been lying too long, and songless, line 41: Time to leap, time to lilt, line 42: Let the sky's boil of anguish burst today, line 43: The pain of earth be soothed.

\subsubsection{Coercive Features in 'Let Earth Pain Be Soothed'}

The coercive features used by the poet are found in his choice of words. In 'Let Earth Pain Be Soothed', twelve of the lines of the poem are beginning with 'Let' which is a command word. 'Let the sky's boil of anguish burst today' is spread all over the poem's lines. All the lines that are started by 'let' are referred to as subjectless verb clauses.

\subsubsection{Pronouns Reference in 'Let Earth's Pain Be Soothed'}

Two pronouns 'it' and 'her' are predominant in the poem 'Let Earth's Pain Be Soothed'. While 'it' refers to the 'rain', 'her' refers to the earth. Kirkpatrick (2010) refers to he, she, it and they as third person personal pronouns and that when they are in the object position, they take the form of him, her, it, and them consecutively. In the poem, 'it' is in the subject position and 'her' in the object position.

\subsubsection{Lexical Items in 'Let Earth's Pain Be Soothed'}

This is one of the linguistically accepted ways by which registers can be differentiated. The classes of words in the lexical items in the poem are given below: 
Adjectives: Many adjectives are used in the poem. The adjectives in 'Let Earth's Pain Be Soothed' include: boil of anguish, miserly, famished, brown, vacant, balded, brewing kitchens, eating halls, scheming boardrooms, retrenching factories, power brothels, parched, rumble, noiseless, songless, falling showers. Some of the adjectives are used attributively and some are used predicatively. Examples for attributive adjectives in the poem are brewing kitchens, falling shower, example for predicative adjective retrenching factories etc.

Nouns: In 'Let Earth's Pain Be Soothed' we have the following nouns: The sky, earth, clouds, horses, hills, plains, dust, kitchens, halls, boardrooms, factories, brothels, throats, cornleaves, womb, stomachs, thunder, children, roofs, seeds, dormitory, soil, cradle, kids. It is discovered here that all the nouns are names of things, places and animals. Some of them are regular and some irregular. Examples of regular nouns are horses, hills, plains etc. while that irregular are children, factories etc. Children in the poem can also be referred to as 'dual gender' (Kirkpatrick 2010:98).

Verbs: In 'Let Earth's Pain Be Soothed', we have the following verbs: carries, lingered, journey, burst, prostrate, cast, provoke, may sing, may heal, may clothe, may swell, may shun, may bath and bawl and brawl, have been silent, has been lying, soothed. Murthy (2012) acknowledge that some verbs are always used with adjectives expressing the quality of the subject. Some examples in the poem reveal different kinds of verbs that such as transitive verbs as in playing kids. It also reveals some nouns that change their form in the plural case as in carries. It is also reveals that many helping verbs were employed to carry out the message as in has been lying, have been silent, may swell etc.

Prepositional Group: In 'Let Earth's Pain Be Soothed', we have the following prepositional groups 'in brewing kitchens', ' in eating halls', 'in scheming boardrooms', 'in retrenching factories' and 'in power brothels'. All the prepositional groups find in the poem are obligatory adverbials because their removal from the sentences can render such sentences ungrammatical.

Adverbial Groups: In 'Let Earth's Pain Be Soothed', we have the following adverbs: Noiseless, songless, miserly, over trees and over hills. Most of the adverbs in the poem are that of manner. Adverb of manner indicates how something happens (Kirkpatrick 2010:69). Examples are: Clouds journey over trees and over hills, Miserly with their liquid treasure.

Coordinators and Subordinators: In Let Earth's Pain Be Soothed, we have two, a coordinator and a subordinator: 'and' and 'that'.

\section{Modal Auxiliaries Usage}

In Let Earth's Pain Be Soothed, 'may' is used as a modal auxiliary to take permission and to express possibility. In this poem, it is used to express the possibility of the rain to fall. It is used in lines $25,27,29,31,33$ and 35 . These lines are sandwiched with the clause 'let it rain', 'let it rain today', which further shows the anticipation of the expectation of the rain by the poet.

\subsubsection{Figurative Expressions in 'Let Earth's Pain Be Soothed'}

In this poem, the title itself shows that the earth is personified and that she is undergoing a painful situation without the rain falling on her. And that it is only when the rain falls that the pains can be soothed. There are series of personification used in the poem. These are seen in the following phrases: the sky carries a boil of anguish, clouds journey over trees, cradle of green, the earth may heal, cornleaves may clothe the hills, the roots may swell the womb of lying plains, stomachs may shun the rumble of thunder, roofs have been silent too long, the seeds noiseless, the earth has been lying too long and songless, brown hills cast vacant looks, provoke the dust, and the pain of earth be soothed. The above mentioned personified elements gave a kind of living effects on the reader of the poem and make the poem real. Hyperbolic expressions are also used in the poem. Examples are: The sky carries a boil of anguish, Let it burst. Euphemism is also used. Examples are: 'The roofs have been silent for too long', 'the seeds noiseless in the dormitory of the soil', 'the earth has been lying too long', and 'songless'. Simile is one of the figures of speech that beautify the diction of the poem. An example is: 'prostrate like famished horses'. Onomatopoeia is also used -'falling showers', 'the rumble of thunder'. Alliteration is another figure of speech used - 'that children may bath and bawl and brawl'.

5.1.8 Symbolism: In Let Earth's Pain Be Soothed, we have the following: boil of anguish, dust, rumble of thunder, clouds journey, liquid treasure, balded plains, cradle of green

\subsubsection{Contextual Semantic Implications of the Features}

From the poem Let Earth's Pain Be Soothed, we are able to deduce that, it has been a long time since they have had rain in the person's area. This is seen in the poet's choice of words. Violent and aggressive words are used for example: boil of anguish, let it burst, provoke the dust, the pain of the earth be soothed. The semantic implications of this is that the person in the area is eager to have rainfall so that parched throats may sing, that the earth may heal her silence, that the cornleaves may clothe the hills, that the roots may swell the womb of lying plains and that children may bath and bawl and brawl.

\subsection{First Rain}

5.2.1 The 'First Rain', has 10 lines which discusses the effects that the first rain has on both human beings and the earth herself. Line 1, a tingling tang awakes the nose, line 4, cooling warmth embraces, line 5, our searching soles, line 9, through her liberated pores, line 10, our earth breathes again. It further discusses the revival that comes upon human lives and even the earth after the rain. The prominent structural patterns are seen in table 2 and figure 2 below. 
Table 2. Prominent Structural Patterns in "First Rain"

\begin{tabular}{ll}
\hline Structural patterns & No of occurrences \% Usage \\
\hline SPC & 11.1 \\
ASP & 33.3 \\
C & 22.2 \\
AC & 22.2 \\
SPA & 11.1 \\
\hline
\end{tabular}

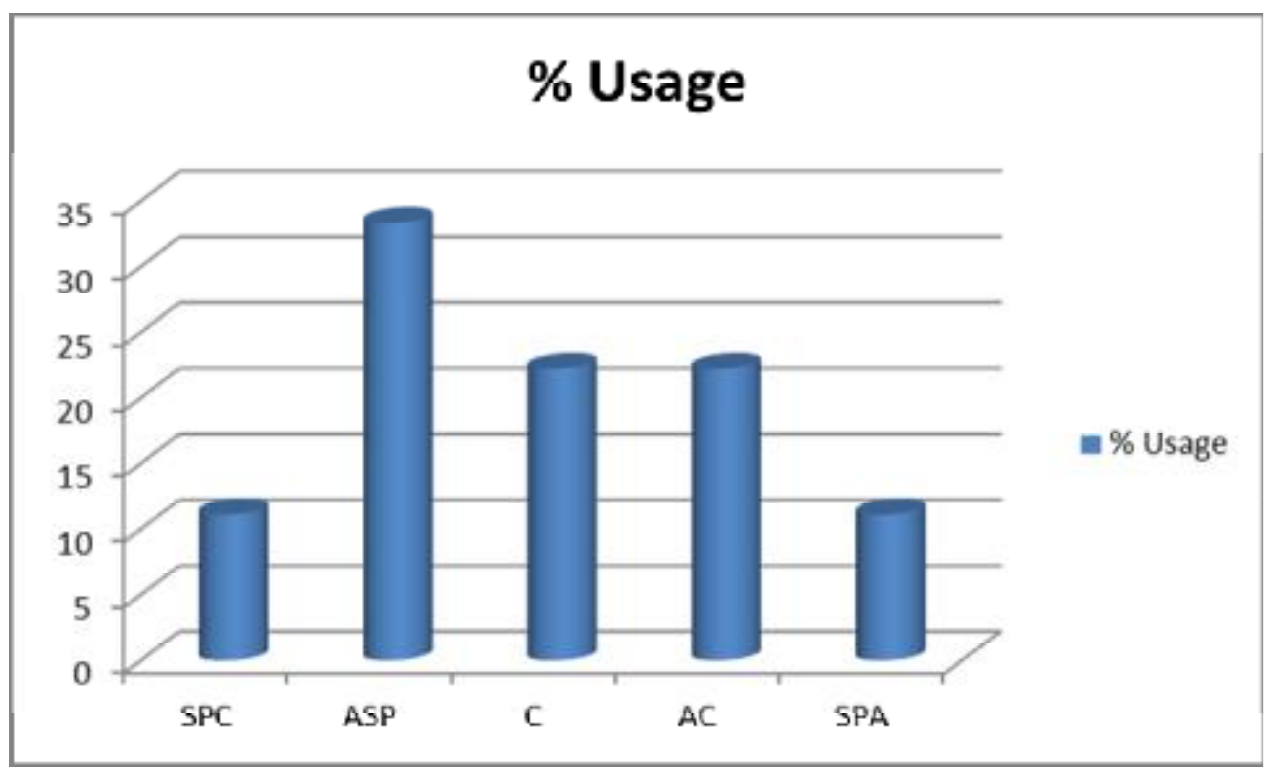

Figures 2. The Percentage Usage of Prominent Structures in "First Rain"

\subsubsection{Metaphorical Features in 'First Rain'}

Almost all the lines in this poem are metaphorical except 'line 8' as we can see below:

line 1: A tingling tang awakes the nose, line 2: when the first rain has just clipped, line 3: the wing of the haughty dust line 4: a cooling warmth embrace, line 5: our searching soles, line 7: like a bootless infantry, line 9: through her liberated pores line 10: our earth breathes again

\subsubsection{Coercive Features in 'First Rain'}

In the other poem, 'First Rain' there is the usage of coercive words in Line 1 of the poem- 'A tingling tang' which explains the prickling or stinging sensation that the first rain causes the nose of everybody. Line 3 , 'The wing of the haughty dust' which explains how arrogantly the dust behaves when the first rain falls.

Pronouns: In 'First Rain', two pronouns are used: 'our' and 'her'. 'our' refers to the human beings and 'her' refers to the earth.

\subsubsection{Lexical Items in 'First Rain}

Nouns: Nouns in 'First Rain' are nose, rain, dust, wing, soles, land, infantry, pores and earth.

Adjectives in 'First Rain' are tingling, haughty, cooling warmth, searching, bootless, and liberated.

Verbs in 'First Rain' are 'awakes' 'clipped', 'embraces', 'rises' and 'breathes'. There is no preposition in 'First Rain'

Adverbs in 'First Rain', we have the following: when and bootless. But there is no modal auxiliary in First Rain.

In First Rain, there is only one coordinator, 'and' throughout the poem.

\subsubsection{Figurative Expressions in 'First Rain':}

In this poem, alliteration used: A tingling tang awakes the nose, 'our searching soles' Personification used:' The wing of the haughty dust', 'a cooling warmth embraces', 'through her liberated pores', 'our earth breathes again'. Simile used: 'like a bootless infantry'. Paradox used: 'a cooling warmth embraces'

5.2.6 Symbolism: In First Rain, bootless infantry, liberated pores, earth breathes are used as symbolism.

\subsubsection{Contextual Semantic Implications of the Features}

In First Rain, the joy of the poet and the effect of the first rain on both human and non-human beings are registered in the poet's choice of words. Words that show these are found in the following lines:

line 1: A tingling tang awakes the nose, line 2: when the first rain has just clipped, line 3: the wing of the haughty dust 
line 4: a cooling warmth embrace, line 5: our searching soles, line 7: like a bootless infantry, line 9: through her liberated poresline 10: our earth breathes again.

\subsection{Meet me at Okeruku}

5.3.1 All lines in 'Meet me at Okeruku' are subjectless. About $40 \%$ of the clauses begin with predicate while the rest $60 \%$ begin with adjunct. Unlike the two earlier discussed poems, the sentence types are non-basic sentences. As Aremo (2004) has said and has earlier been referred to in this paper that non-basic sentences are formed through grammatical operations like movement, deletion and insertion. There are twelve non-basic statements in the poem. Movement operation occurred in lines: 1, 4, 9, 11. In these lines, the predicators come before the subjects. Eight of the lines in the poem are adverbial clauses. The lines are 2, 3, 5, 6, 7, 8, 10 and 12. The prominent structural patterns are represented in the table 3 and figure 3 below.

Table 3. Prominent Structural Patterns in "Meet me at Okeruku"

\begin{tabular}{ll}
\hline Structural Patterns & Number of Occurrences \\
\hline PSAA & 11.1 \\
PA & 11.1 \\
PSAS & 11.1 \\
PAS & 11.1 \\
ASPA & 22.2 \\
AS & 33.3 \\
ASS & 11.1 \\
ASPAA & 11.1 \\
ASAS & 11.1 \\
\hline
\end{tabular}

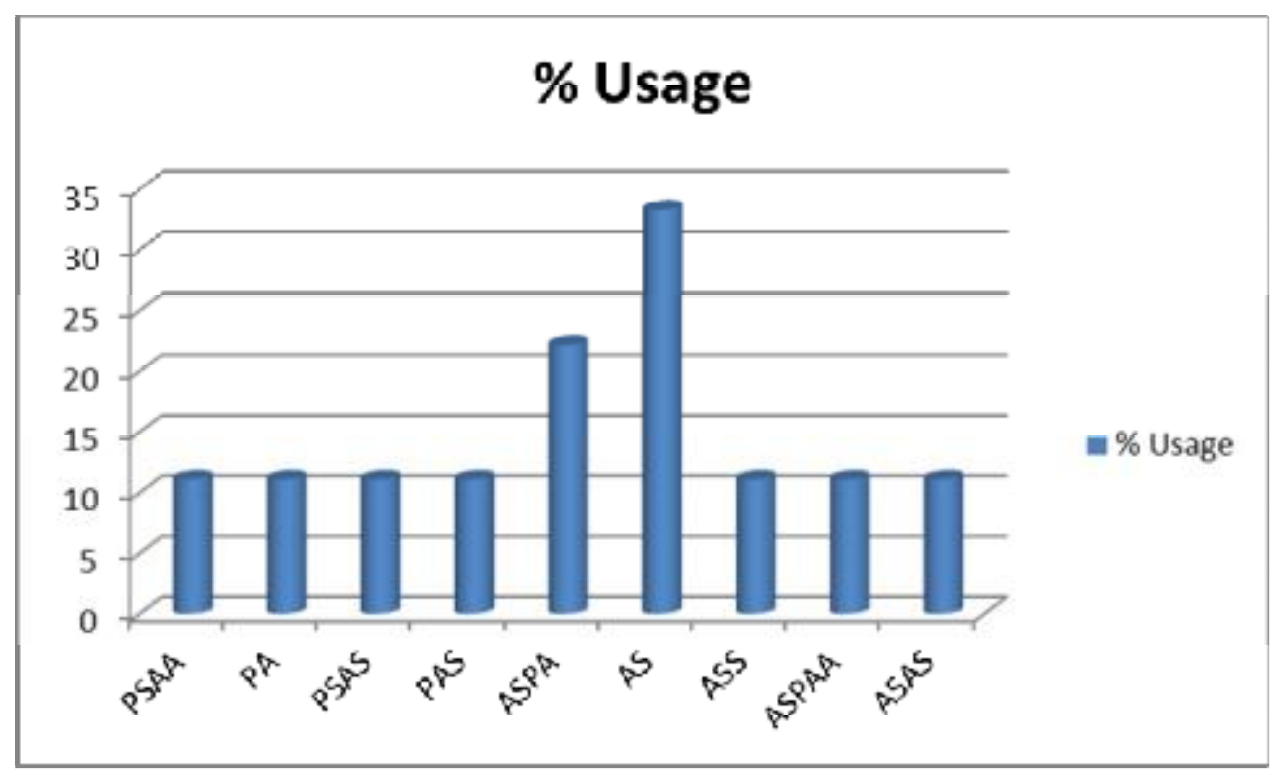

Figures 3. The Percentage usage of Prominent Structures in "Meet me at Okeruku"

\subsubsection{Metaphorical Features in 'Meet me at Okeruku'}

Sentence /Clause Typology in the Poem

This poem describes a physical feature that exists in a town in the South Western part of Nigeria. Okeruku is a place in one of the towns in Ekiti State. The poet revealed the characteristics of Okeruku. He described the earth of the place as a reddening powder or dust that metaphorically beautifies houses in the dry harmattan season. But when it rains the dust becomes lump of mud and becomes sticky that toemarks will be secretly written on the earth until when another rain, which the poet refers to as the liquid eraser, falls. Most of the lines in this poem are also metaphorical, only lines 1, 7, and 12 are not. Lines 2, 3, 4, 5, 6, 8, 9, 10, and 11 are metaphorical. Line 2: where earth is one compact, Lines 3: of reddening powder, Line 4: daubed coquettishly, Line 5: on the harmattan brow, Line 6: of trembling houses, Line 8: When this dust is clod and clay, Line 9: Show me hurried toemarks, Line10: on the ciphered pages of narrow alleys, Line 11: awaiting the liquid eraser. It is noted that as usual in the three poems, two seasons are considered, the harmattan and the rainy seasons. Lines 2-6 expresses how red powder of the earth, due to dryness, is raised on the roofs of houses and make them look like a woman who frequently tries to attract the attention of men as described by the poet. The poem is characterized by good choice of words and run-on lines which makes it rhythmic and sonorous. 


\subsubsection{Coercive Features in 'Meet me at Okeruku'}

Just as we have coercive features in the first lines of the aforementioned poems, so is the situation with the first line of this poem too. Line 1: Meet at Okeruku is a 'command' in sentence typology. Here, the poet is commanding the 'rain' to meet him at Okeruku. Line 9 also displays another 'command', 'show me hurried toemarks'. Line 10: 'on the ciphered pages of narrow alleys', which is the place where the toemarks are to be shown. He further explains that there is a liquid eraser that will come and erase all the toemarks which is 'rain'.

\subsubsection{Lexical Items in 'Meet me at Okeruku',}

Pronouns: In 'Meet me at Okeruku', the pronoun 'me' is used twice in the poem. This pronoun is used immediately after the words depicting 'command in the poem. Line 1: 'Meet me', line 9: 'Show me'. This shows the eagerness and the anxiousness of the poet in awaiting rainfall and it also shows how important rain is to human's existence.

Nouns: Nouns in 'Meet me at Okeruku' are the following: Okeruku, earth, powder, harmattan, brow, houses, rain, toemarks, pages, alleys, eraser and shower.

Adjectives: In 'Meet me at Okeruku' we have compact, reddening, coquettishly, trembling, clod, clay, hurried, ciphered, narrow and liquid as adjectives.

Verbs in 'Meet me at Okeruku' we have the following verbs: 'meet', 'daubed', 'show', 'awaiting'. There are auxiliary verbs too: 'is' and 'are'.

Adverbs: In 'Meet me at Okeruku' 'of reddening powder', 'on the harmattan brow', 'of trembling houses', 'on the ciphered pages of narrow alleys' and 'of the next shower'. In 'Meet me at Okeruku' we have all the adverbial groups that are present as obligatory adverbial since they are identified in the prepositional groups. Asiyanbola (2013) opines that when a nominal group is governed by a preposition, then we have obligatory adverbials. All that had been mentioned under the prepositional group as examples here too. In 'Meet me at Okeruku', 'and' is used twice in lines 7 and 8. In Meet me at Okeruku the auxiliary verbs used are the verb 'be' which are 'is' and 'are'. 'is' is used twice and 'are' is used once.

\subsubsection{Figurative Expressions in 'Meet me at Okeruku'}

The title of the poem shows that the poet really needs the want it to fall by force. The title shows that a command is passed across to the rain and the place of meeting is even mentioned by the poet. Personification is used in some of the lines of the poem e.g 'on the harmattan brow' and 'of trembling houses'. This is to bring reality in the imagination of the poet to the readers of the poem. The personified elements are found in lines 'harmattan' and 'houses'. Hyperbolic elements are found in: daubed coquettishly, show me hurried toemarks, the ciphered pages of narrow alleys. Paradox is used in 'awaiting the liquid eraser'. Metaphor is used in almost all the lines of the poem except lines 1, 7.

5.3.6 Symbolism

In Meet me at Okeruku, we have the following symbolism in 'where earth is one compact', of reddening powder, 'daubed coquettishly', 'on the harmattan brow', 'of trembling houses', 'when this dust is clod and clay', 'show me hurried toemarks', 'on the ciphered pages of narrow valleys' and 'awaiting the liquid eraser'.

\subsubsection{Contextual Semantic Implications of the Features}

In 'Meet me at Okeruku' expectation of rain is also shown in the poet's use of words. This is found in the following phrases: 'where the earth is one compact', 'of reddening powder, 'daubed coquettishly', 'on the harmattan brow'. He further explains what will happen when the expected rains come, in line 8:'when this dust is clod and clay' and that all hurried toemarks will on the ciphered pages of narrow alleys be erased away by the liquid called rain. There is an allusion here in that liquid eraser is used to represent 'rain'. We can see the eagerness in the diction of the poet. the semantic implications that we have in this poem is that, when rain comes, all effects of dryness found on roofs and on the earth will vanish with immediate effect and their environment will be relieved of dust and its effects on human beings.

\section{Comparative Analysis of the Three Poems}

\subsection{Percentage Usage of Lexical Items in the Poems}

This is to show the percentage usage of lexical items used in the three poems.

Table 4. Shows the \% of Occurrences of Word Classes

\begin{tabular}{llll}
\hline Classes of Words & Let Earth Pain Be Soothed & First Rain & Meet me at Okeruku \\
\hline Nouns & 53.3 & 20 & 26.6 \\
Adjectives & 48.3 & 19.3 & 32.2 \\
Verbs & 59.2 & 18.5 & 22.2 \\
Prepositions & 50 & 00 & 50 \\
Adverbs & 36.3 & 18.1 & 45.4 \\
\hline
\end{tabular}




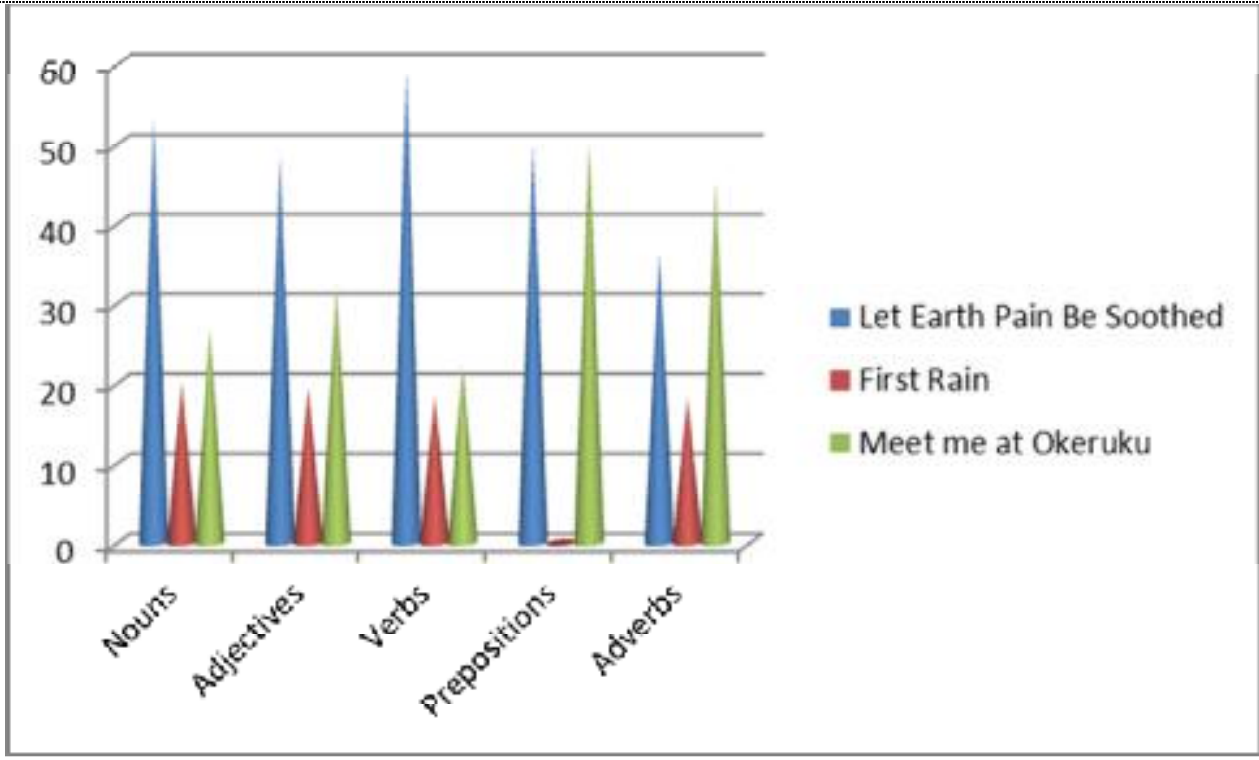

Figure 4. The Representation of Percentage of Occurrences of Word Classes

From Table 4 and Figure 4 above, it is clearly seen that we have higher usage of all the word classes in the poem Let Earth Pain Be Soothed. This might be due to the greater number of lines contained in the poem. But between the remaining two poems, we discover that in the usage of prepositions, 'Meet me at Okeruku' has 50\% usage, while 'FirstRain' has none there. In the usage adverbs, 'Meet me at Okeruku' has $45.4 \%$ and 'First Rain' has $18.1 \%$. This might be because 'Meet me at Okeruku' refers to places that will have the effect of rain on them most, when it comes. The adjectives take $32.2 \%$ in 'Meet me at Okeruku' while 'First Rain' has $19.3 \%$. It also reveals clear differences between the two poems in the use of nouns, verbs. The difference in the use of adverbs is not much in the two poems. It distinctively reveals that there is no preposition at all in First Rain. The fact remains that the usage of lexical items depends on the length of the poem and the message of the poet.

\subsection{Percentage Usage of Figures of Speech in the three Poems}

Table 5. Shows the \% Usage of Figures of Speech in the poems.

\begin{tabular}{llll}
\hline Figures of Speech & Let Earth Pain Be Soothed & First Rain & Meet me at Okeruku \\
\hline Personification & 70 & 20 & 10 \\
Hyperbole & 40 & 00 & 60 \\
Euphemism & 100 & 00 & 00 \\
Simile & 50 & 50 & 00 \\
Onomatopoeia & 100 & 00 & 00 \\
Alliteration & 33.3 & 66.6 & 00 \\
Paradox & 00 & 50 & 50 \\
Metaphor & 00 & 00 & 100 \\
\hline
\end{tabular}

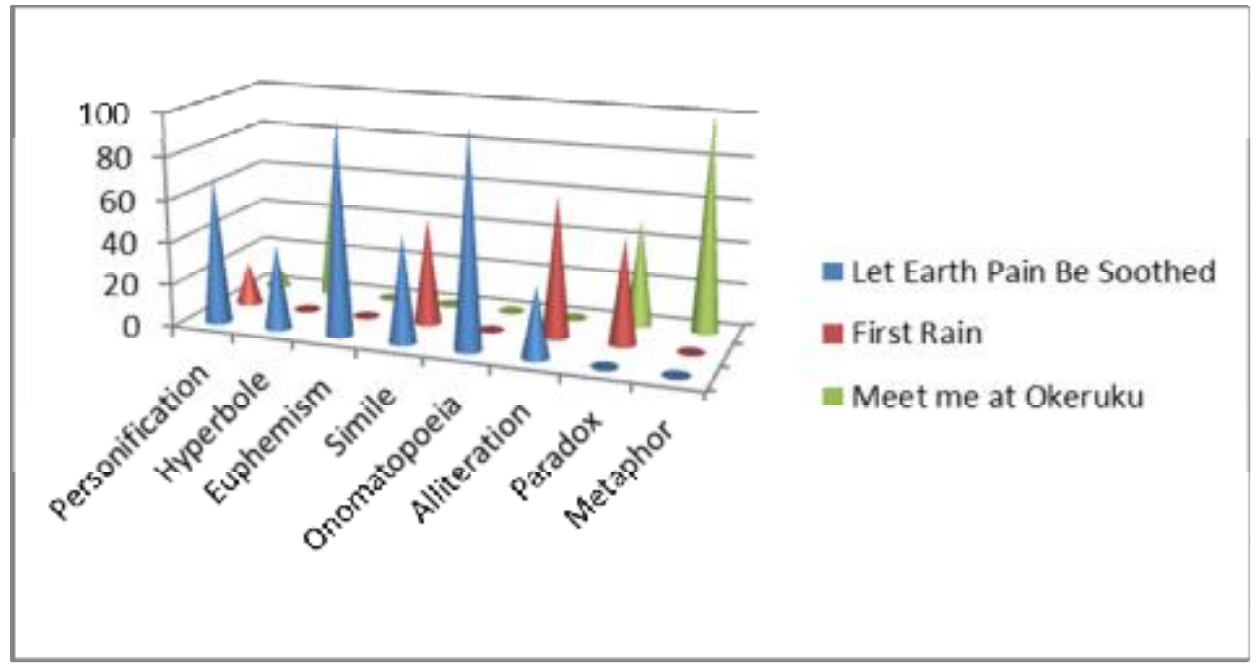

Figure 5. The Representation of the \% Usage of Figures of Speech in the three poems 
From Table 5 and Figure 5 above, personification is highly used in 'Let Earth's Pain Be Soothed'. Even the title is personified. This might be due to the greater number of lines of the poems. The usage of all other figures of speech is low in two of the poems: First Rain and Meet me at Okeruku. Hyperbole, Euphemism and onomatopoeia are not used in the 'First Rain' at all while paradox is not used at all in 'Let Earth's Pain Be Soothed'. In the use of 'simile', there is uniformity in two of the poems even though their number of lines varies. In the use of alliteration and paradox, 'First Rain' which has fewer numbers of lines has the higher usage of the two figures of speech. The usage of figures of speech reveals that the beauty of any poem lies in the choice of words and the figures of speech used by the poet. The poet uses run-on lines in the two poems and this brings out the coherence and sonorous effects found in the poems.

\section{Conclusion}

Let earth's pain be soothed reveals that imperatives in which 'let' is no more than an introductory particle should be kept separate from the ordinary $2^{\text {nd }}$ person imperative of 'let' as a transitive verb. From Figure 1, we discover that the SPC pattern has $21 \%$ number of occurrences, which is the highest pattern of the structures. This reveals that there are more simple declarative clauses in the poem. The PSP pattern takes the second position. These lines are those with 'let', which is a command at the beginning. These imply clauses which normally have no overt grammatical subject and whose verbs are in the imperative mood. The clauses are subjectless. In this poem, we discover that most of the lines have only one subject and one predicate in each clause and complement. Also the result reveals that there are striking regularities in the relative position of elements: subject first, predicate second and complement in a post-verb position as seen in lines 1, 3, 7, 14, 22, 27, 29, 33 and 36 of the poem. It further reveals that, in some of the lines of the poem, the adverbials are closely tied to the predicate as seen in lines 5, 9, 10, 24, 32, 40 and 42 . It also reveals that from line 16 through line 21, we have verbless clauses because the subjects of these lines are followed immediately by adjuncts. So the structure is (S A). The First Rain reveals that the ASP structural pattern has the highest number of occurrences; this is seen in lines 2, 4, 6, 7 and 9 of the poem. Two of the lines in the poem are solely complements. It also reveals that only one line of the poem is a simple declarative clause and that is line 1. Verbless clauses are lines 3, 5, 7 and 9. 'Meet me at Okeruku' reveals that all the lines of the poem are subjectless. There is no simple declarative clause. Four of the lines of the poem begin with predicate and the remaining six lines begin with adjunct. Most of the adjuncts are adverbials, e.g lines 2, 5, 7, 8 and 10. Generally, at the grammatical level, kinds of clauses and sentences used have been examined with their functions. At the lexical level, deixis and word classes were x-rayed in the text. The figurative expressions used in the three poems were also taken into cognizance. But the benefit derived from this study is that it exposes what a linguist does to literature to measure the quality of the language employed. It has also revealed the concept of cohesion, which is needed by the literary critic in order to appreciate literature. Lastly, it reveals that linguistic stylistics has its major purpose of relating language use in literary texts to its artistic function. In conclusion, it is observed that some things are common to the three poems. First, 'rain' is a phenomenon that is common to all the poems. Second, the 'dry effect of lack of rain' on all that is expectant of it, and third, the cooling effect of the rain after it falls on all that is expectant of it.

\section{References}

Awonuga, C. O. (1988). Linguistic Stylistics as a Method of Literary Interpretation, Ife Studies in English Language, 2(1), 38-48.

Aremo, B. (2004). An Introduction to English Sentences 1 \&11: Ibadan: SCRIBO Publications Limited.

Asiyanbola, A. (2012). Basic English Grammar for Universities: An Introduction, Lagos: Olivetree Publishing Venture.

Chapman, R. (1973). Linguistics and Literature: An Introduction to Literary Stylistics: London: Edward Arnold.

Crystral, D. (1971). Linguistics, England: Penguin Books Ltd.

Hassan, R. (1985). Linguistics, Language and Verbal Art: Greelong, Victoria: Deakin, UP Ltd.

Kirkpatrick, B (2010) Correct Grammar Correct English. Scotland: Waverley Books Ltd.

Leech, G .N., \& Short, M. H. (1981). Style in Fiction: A Linguistic Introduction to English Fictional Prose. London: Longman.

Murthy, J.D. (2012). Contemporary English Grammar. Lagos, Nigeria: Book Master.

Randolph Quirk et al. (1976). A Grammar of Contemporary English. London: Longman Group Ltd. 